\title{
Analisis Komoditas Pertanian Unggulan dan Arahan Pengembangannya di Kabupaten Pakpak Bharat
}

Analysis of Superior Agri culture Commodities of Development Direction in PakPak Bharat

Lukas Sebayang

Balai Pengkajian Teknologi Pertanian Sumatera Utara, Medan 20143

Corresponding Author : mabayang2001@yahoo.com

\begin{abstract}
The Development of competitive commodities in a region are expected to improve added value of the commodities, to increase society income and to improve regional economic conditions. This study was conducted (1) to analyse competitive commodities of agriculture in each district, (2) to analyse potential land for competitive commodities development (3) to analyse regional hierarchies (4) to formulate direction of competitive commodities development plan. The competitive commodities were obtained using Location Quotient (LQ) and Shift Share Analysis (SSA). Analysis potential land for competitive commodities development was analysed using land availability and suitability and geographical information system. Regional hierarchy was analysed using schalogram method. Competitive commodities development direction considered based on potential land, regional hierarcy, compactness of land and local government policy. The results showed that competitive commodities in every district were uncaria gambier, rice farming and orange plant. The direction development of coffee was given priority in STTU Jehe subdistrict area of 4.512,56 ha. Food crops was given priority in Pangindar subdistrict area of 2.182,81 ha.
\end{abstract}

Keywords: development, competitive commodities, potential land

Pengembangan komoditas unggulan secara terintegrasi pada suatu wilayah diharapkan dapat meningkatkan nilai tambah komoditas, pendapatan masyarakat dan perekonomian wilayah. Tujuan penelitian ini adalah untuk menganalisis komoditas unggulan, potensi pengembangan untuk komoditas unggulan, analisis hirarki wilayah dan arahan rencana pengembangan komoditas unggulan. Komoditas unggulan didapatkan dengan analisis Location Quotient (LQ) dan Shift Share Analysis (SSA). Lahan yang berpotensi pengembangan dianalisis dengan arahan ketersediaan dan kesesuaian lahan serta sistem informasi geografis, Hiraki wilayah dengan analisis skalogram. Arahan rencana pengembangan komoditas unggulan ditetapkan berdasarkan pertimbangan lahan yang berpotensi pengembangan, hirarki wilayah, lahan yang kompak dan kebijakan pemerintah daerah. Hasil penelitian menunjukkan komoditas unggulan adalah gambir, padi sawah dan jeruk. Pengembangan komoditas unggulan tanaman perkebunan diarahkan di Kecamatan STTU Jehe seluas 4.512,56 ha. Pengembangan komoditas unggulan tanaman pangan diprioritaskan di Kecamatan Pangindar seluas 2.182,81 ha.

Kata kunci: pengembangan, komoditas unggulan, lahan potensial 


\section{PENDAHULUAN}

Komoditas unggulan merupakan salah satu komoditas pertanian yang memiliki nilai strategis berdasarkan kemampuan sumberdaya manusia, infrastruktur, kondisi sosial budaya), sosial ekonomi dan kelembagaan (penguasaan teknologi), pertimbangan fisik (kondisi tanah dan iklim), untuk dikembangkan di suatu wilayah (Sitorus et al. 2014).

Sektor utama atau sektor primer yang berbasis pertanian di Kabupaten Pakpak Bharat perlu ditingkatkan nilai tambahnya agar perekonomian masyarakat meningkat. Salah satu cara yang dapat dilaksanakan adalah dengan mengembangkan komoditas pertanian unggulan.

Pendekatan komoditas unggulan dilandasi pada pendapat bahwa yang perlu dikembangkan di sebuah wilayah/daerah adalah menjual hasil produksi dan kemampuan berproduksi tersebut secara efektif dan efisien dengan sumber daya wilayah/daerh tersebut untuk diekspor dan menghasilkan kekayaan daerah serta penciptaan peluang kerja (Ameriyani, 2014). Dengan demikian perekonomian wilayah/daerah akan bergerak lebih cepat sehingga akan meningkatkan pendapatan masyarakat.

Perencanaan pengembangan komoditas pertanian sangat diperlukan dengan penentuan kesesuaian lahan dengan persyaratan tumbuh tanaman (Boix dan Zinx, 2008). Pengembangan komoditas unggulan perlu memperhatikan ketersediaan lahan dan kesesuaian lahan. Pengembangan komoditas unggulan berdasarkan hasil evaluasi kesesuaian lahan akan menghasilkan pertumbuhan dan produksi sesuai dengan kelas kesesuaian lahannya. Arahan pengembangan komoditas unggulan perlu dilakukan agar pengembangan komoditas unggulan lebih terarah pada lahan-lahan yang berpotensi pengembangan.
Tujuan penelitian ini adalah (1) Menganalisis komoditas pertanian unggulan di tiap kecamatan (2) Menganalisis lahan yang berpotensi pengembangan untuk komoditas unggulan, (3) Menganalisis hirarki wilayah, (4) Menyusun arahan rencana pengembangan komoditas unggulan.

Kabupaten Pakpak Bharat merupakan kabupaten hasil pemekaran dari Kabupaten Dairi pada tahun 2003. Pendapatan Domestik Regional Bruto (PDRB) kabupaten ini pada tahun 2017 tercatat sebesar 996,48 milyar rupiah, dimana sektor pertanian masih sebagai kontributor utama dengan peranan mencapai $55,15 \%$ selanjutnya diikuti oleh sektor Administrasi sebesar $12,85 \%$, sektor perdagangan sebesar $11,27 \%$, konstruksi $10,50 \%$ dan 10,23\% sektor lainnya (BPS Pakpak Bharat, 2018). Oleh sebab itu sektor pertanian mempunyai peranan strategis dalam struktur pembangunan perekonomian di kabupaten ini.

Luas lahan pertanian Kabupaten Pakpak Bharat adalah 101.754 ha, terdiri dari 1.296 ha lahan sawah dan 101.754 ha lahan kering (BPS Pakapak Bharat, 2018). Berbagai tipe zona agroekosistem yang terdapat di kabupaten ini mulai dari lahan dataran rendah, dataran medium dan dataran tinggi tersebar di seluruh kecamatan. Lahan pertanian umumnya diusahakan petani dengan menanam tanaman semusim (sayuran, bungabungaan, padi dan palawija) dan tanaman tahunan (buah-buahan, perkebunan, tanaman pencegah erosi).

Sektor pertanian di Kabupaten Pakpak Bharat masih terkonsentrasi pada kegiatan on farm (budidaya). Sektor pertanian di Kabupaten Pakpak Bharat masih terkonsentrasi pada kegiatan on farm (budidaya). Komoditas tanaman tahunan utama yaitu gambir, jeruk dan kopi. Komoditas tanaman pangan utama yaitu padi sawah, ladang dan jagung. Produksi tanaman pangan ini meningkat sekitar $25 \%$ 
dari tahun sebelumnya (Deperindag Pakpak Bharat, 2018).

\section{BAHAN DAN METODE}

\section{Lokasi dan Waktu}

Penelitian dilaksanakan di Kabupaten Pakpak Bharat, Propinsi Sumatera Utara yang secara geografis terletak pada titik koordinat $2^{\circ} 15^{\prime} 00^{\prime \prime}$ $3^{\circ} 32^{\prime} 00^{\prime \prime}$ Lintang Utara dan 96 $06^{\circ} 00^{\prime \prime}$ 98 $31^{\prime} 00^{\prime \prime}$ Bujur Timur. Karena terletak dekat garis khatulistiwa, kabupaten Pakpak Bharat tergolong ke daerah beriklim tropis. Ketinggian 250 - 1032 di atas permukaan laut dengan kondisi geografis berbukitbukit. Secara administratif Kabupaten Pakpak Bharat terdiri dari 8 kecamatan yaitu Kecamatan Salak, Sitellu Tali Urang Jehe (STTU Jehe), Pangindar, Sitellu Tali Urang Julu (STTU Julu), Pergettenggetteng Sengkut (PGGS), Kerajaan, Tinada dan Siempat Rube (Gambar 1). Penelitian dilaksanakan pada bulan Maret 2015 sampai dengan Nopember 2015.

\section{Jenis Data dan Alat}

Data yang digunakan dalam penelitian ini berupa data sekunder dan data primer. Data sekunder berupa luas tanam komoditas perkebunan tahun 2009-2014, luas panen komoditas tanaman pangan dan hortikultura tahun 2009-2014, Jumlah keluarga pertanian, satuan peta tanah skala 1:250,000, citra spot 6 tahun 2014, peta administrasi Kabupaten Pakpak Bharat skala 1:250,000, peta RTRW Kabupaten Pakpak Bharat skala 1:250,000, peta penggunaan lahan tahun 2014, peta kawasan hutan, peta ketinggian, peta temperatur, data curah hujan, peta kontur, peta tekstur tanah, peta kedalaman tanah, salinitas, peta kelas lereng, jumlah penduduk, fasilitas pendidikan, fasilitas kesehatan, fasilitas perekonomian, sarana dan produksi pertanian.

Data primer diperoleh dari survei dan wawancara. Survei dilakukan untuk memvalidasi lokasi eksisting komoditas unggulan. Wawancara dilakukan melalui wawancara semi terstruktur dengan ketua kelompok tani yaitu $10 \%$ dari kelompok tani untuk analisis usahatani dengan teknik Purposive Sampling. Alat yang digunakan berupa Global Positioning System, komputer dengan softwareMS-Office 2010 dan sistem informasi geografis

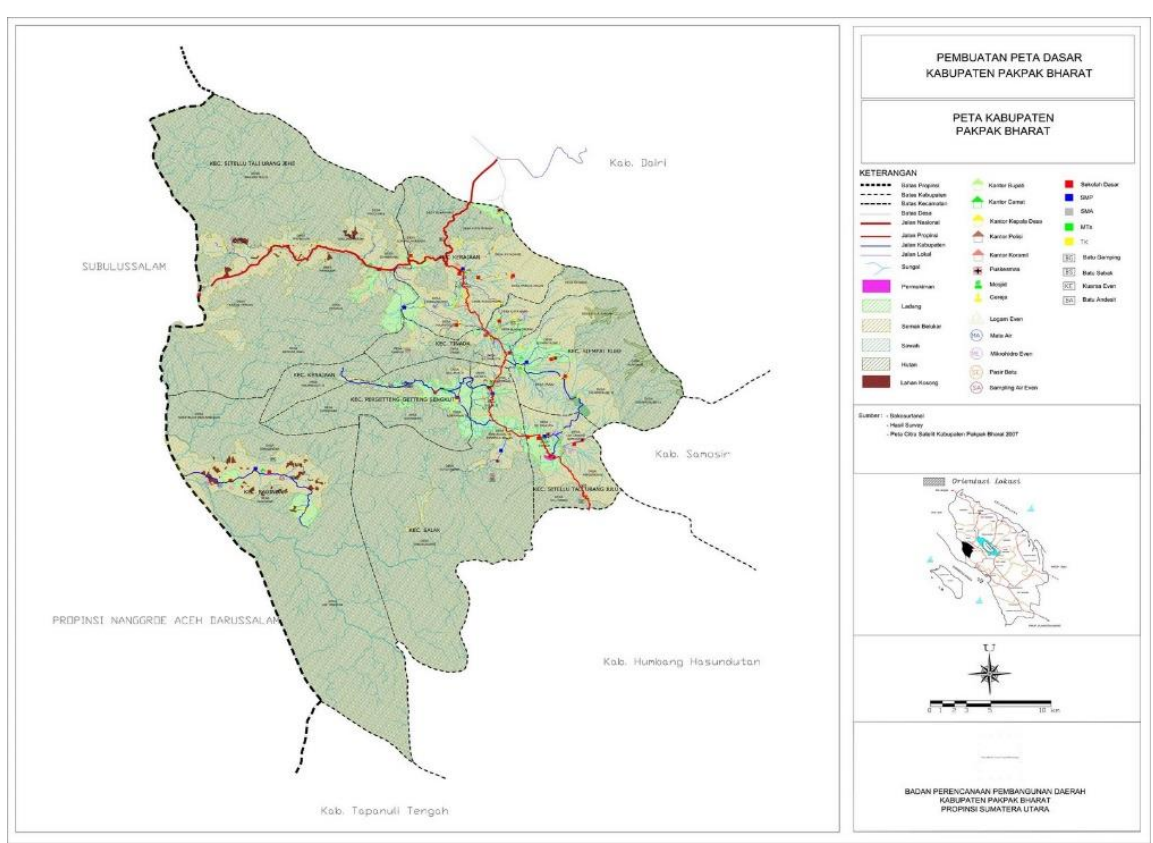

Gambar 1. Peta Administrasi Kabupaten Pakpak Bharat 
Analisis

\section{Identifikasi Komoditas Unggulan di Setiap Kecamatan}

Komoditas unggulan ditentukan dengan metode Location Quotient (LQ) dan Shift Share Analysis (SSA). LQ merupakan metode yang efisien dan efektif untuk menentukan konsentrasi komoditas di beberapa wilayah serta berguna untuk pengambil kebijakan atau peneliti dapat merancang dan merencanakan atau mengevaluasi pertumbuhan suatu wilayah (Chiang, 2008). Komoditas unggulan adalah komoditas yang memiliki nilai LQ $>1$ dan komponen SSA Diffrential Shift (DS) positif. Metode ini sudah banyak digunakan dalam berbagai penelitian, antara lain Manik et al (2013), Yustian et al. Rumus SSA yang digunakan adalah

$S S A=\left(\frac{X . .(t 1)}{X . .(t 0)}-1\right)+\left(\frac{X . j(t 1)}{X . j(t 0)}-\right.$ a b

Dimana :

$a \quad$ : Komponen regional share

$b \quad$ : komponen proportional shift

$c \quad$ : Komponen differential shift

$X . . \quad$ : Nilai Jumlah aktivitas wilayah secara agregat

$X . j \quad$ : Nilai Jumlah aktivitas tertentu di unit wilayah agregat

$X i j \quad$ : Nilai wilayah ke i dan aktivitas ke $\mathrm{j}$

t1 : Titik tahun akhir (tahun 2014)

to : Titik tahun awal (tahun 2009)

Analisis Ketersediaan Lahan

Ketersediaan lahan dianalisis dengan mengoverlay satuan peta tanah dengan peta kawasan hutan lindung, peta RTRW Kabupaten Pakpak Bharat tahun 2012-2032 (peta pola ruang, peta kawasan strategis), peta penggunaan lahan. Kawasan hutan lindung dan kawasan strategis dikeluarkan dari satuan peta tanah. Peta pola ruang yang dipertahankan adalah peruntukan untuk
(2014), Raharjo et al. (2015), Setiawati et al. (2016).

Rumus LQ yang digunakan menurut Blakely(1994) adalah

$L Q i j=\frac{X i j / X i .}{X . j / X . .}$

Dimana :

LQij : Nilai LQ untuk komoditas ke-j di kecamatan ke-i di Kabupaten Pakpak Bharat

$X i j \quad$ : Komoditas ke-j di kecamatan kei di Kabupaten Pakpak Bharat

$X i . \quad$ : Jumlah komoditas di kecamatan ke-i di Kabupaten Pakpak Bharat

$X . j \quad$ : Komoditas ke-j di Kabupaten Pakpak Bharat

$X . . \quad$ : Jumlah komoditas di Kabupaten Pakpak Bharat

$\left.\frac{X . .(t 1)}{X . .(t 0)}\right)+\left(\frac{X i j(t 1)}{X i j(t 0)}-\frac{X . j(t 1)}{X . j(t 0)}\right)$

$\mathrm{C}$

perkebunan dan pertanian. Peruntukan untuk pertanian kemudian di bagi lagi menjadi peruntukan untuk tanaman pangan dan hortikultura.

Analsis Kesesuaian Lahan untuk Komoditas Unggulan

Pengkelasan dan penilaian kelas kesesuaian lahan dilakukan pada lahanlahan yang ada dengan cara membandingkan persyaratan yang dibutuhkan oleh komoditas pertanian unggulan yang akan dikembangkan dengan karakteristik atau kualitas lahan yang dimiliki oleh lahan yang akan digunakan (FAO 1976). Analisis kesesuaian lahan dilakukan pada peta lahan yang tersedia dengan analisis sistem informasi geografis. Metode ini sudah banyak digunakan dalam berbagai penelitian, antara lain Wirosoedarmo et al. (2011), Ogunlade et al. (2012), Widiatmaka et al. (2014), Yanis et al. 
(2014) dan Nowar et al. (2015). Analisis dilakukan dengan metode overlay antara peta satuan tanah, peta temperatur, peta curah hujan, peta kelas lereng, peta tekstur tanah, peta kedalaman tanah, peta bahaya erosi, kerawanan banjir dan salinitas. Adapun pelaksanaan kriteria kesesuaian lahan yang dipakai mengunakan kriteria dari Balai Besar Penelitian dan Pengembangan Sumberdaya Lahan Pertanian tahun 2011 (BBPPSDLP,2011).

Lahan Yang Berpotensi Pengembangan Untuk Komoditas Unggulan

Lokasi eksisting komoditas unggulan didapatkan dari proses digitasi visual on screen citra spot 6 liputan tahun 2014 menggunakan sistem informasi geografis dan divalidasi dengan survei menggunakan GPS. Pelaksanaan digitasi secara visual dilaksanakan menurut pola, rona, warna dan asosiasi (Lillesand dan Kiefer, 1993). Potensi pengembangan komoditas unggulan di dapatkan dari hasil lahan yang tersedia dan sesuai dikurangi (di overlay) dengan lokasi eksisting komoditas unggulan.

Analisis Hirarki Wilayah

Hirarki wilayah tiap kecamatan ditentukan dengan metode skalogram mengikuti Panuju dan Rustiadi (2013) dan Sitorus et al (2015). Dengan menggunakan metode ini semua jumlah penduduk, fasilitas pendidikan, fasilitas kesehatan, fasilitas ekonomi, fasilitas pertanian, dicatat dalam bentuk matriks dan dihitung berdasarkan Indeks Perkembangan Kecamatan (IPK). IPK dikelompokkan ke dalam tiga kelas hirarki, yaitu kelas hirarki I (tinggi), kelas hirarki II (sedang) dan kelas hirarki III (rendah). Penentuannya didasarkan atas nilai standar deviasi IPK (St dev), nilai rataan IPK, dan nilai rataan IPK dijumlah dengan dua kali nilai standar deviasinya.
Arahan Rencana Pengembangan

Komoditas Unggulan

Arahan rencana pengembangan komoditas unggulan dilakukan berdasarkan pertimbangan lahan yang berpotensi pengembangan paling luas, kelas kesesuaian lahan paling tinggi, lahan yang kompak, kelas hirarki wilayah kecamatan paling tinggi dan arahan kebijakan pemerintah daerah. Arahan rencana pengembangan komoditas unggulan dipetakan dengan menggunakan sistem informasi geografis.

\section{HASIL DAN PEMBAHASAN}

\section{Identifikasi Komoditas Unggulan}

Komoditas pertanian unggulan merupakan komoditas yang memiliki nilai strategis berdasarkan pertimbangan fisik (kondisi tanah dan iklim) maupun sosial ekonomi dan kelembagaan (penguasaan teknologi, kemampuan sumberdaya manusia, infrastruktur, kondisi sosial budaya) untuk dikembangkan pada suatu wilayah (Sitorus et al. 2014). Data yang digunakan untuk menentukan komoditas unggulan adalah data luas tanam (ha) untuk komoditas perkebunan, luas panen (ha) untuk komoditas tanaman pangan dan hortikultura tahun 2009-2014.

Tabel 1 terlihat Kecamatan Kerjaan terdapat paling banyak jenis komoditas unggulan perkebunan, pangan dan hortikultura kemudian diikuti Kecamatan Salak. Sedangkan di Kecamatan Pangindar tidak memiliki komoditas hortikultura unggulan karena usahataninya hanya pada tanaman perkebunan dan tanaman pangan saja. Jika suatu kecamatan yang memiliki hanya satu komoditas unggulan saja, maka komoditas tersebut ditetapkan sebagai komoditas unggulan utama. Sedangkan jika suatu kecamatan memiliki lebih dari satu komoditas unggulan maka pemilihan komoditas unggulan utama ditetapkan berdasarkan kriteria (1) jumlah petani paling banyak (2) keuntungan usaha tani 
paling tinggi (3) luas tanam/luas panen paling besar dan (4) sistem pengelolaan monokultur.

Tabel 1. Hasil Analisis Komoditas Unggulan di Kabupaten Pakpak Bharat

\begin{tabular}{cllll}
\hline \multirow{2}{*}{ No } & \multirow{2}{*}{ Kecamatan } & \multicolumn{3}{c}{ Komoditas Unggulan } \\
\cline { 3 - 5 } & & \multicolumn{1}{c}{ Perkebunan } & Tanaman Pangan & \multicolumn{1}{c}{ Hortikultura } \\
\hline 1 & Salak & gambir,kopi arabika & padi sawah,jagung & jeruk,durian,nenas \\
2 & STTU Jehe & gambir,karet & padi sawah & jeruk,durian \\
3 & Pangindar & karet, kelapa sawit & padi gogo & - \\
4 & STTU Julu & kopi arabika & padi sawah & Jeruk \\
5 & PGGS & gambir, karet & padi sawah,jagung & Jeruk \\
6 & Kerajaan & gambir,karet,kopi & padi sawah,jagung & jeruk,durian \\
& & arabika, kemenyan & & \\
7 & Tinada & Karet & padi sawah & jeruk,durian \\
8 & Siempat Rube & kopi arabika & padi sawah,jagung & jeruk,nenas \\
\hline
\end{tabular}

Tabel 2. Komoditas Unggulan Utama dan Penunjang di Kabupaten Pakpak Bharat

\begin{tabular}{clll}
\hline \multirow{2}{*}{ No } & \multicolumn{1}{c}{ Kecamatan } & \multicolumn{2}{c}{ Komoditas Unggulan } \\
\cline { 2 - 3 } Perkebunan & Gambir & Penunjang \\
1 & Salak & Gambir & Karet \\
2 & STTU Jehe & Karet & kelapa sawit \\
3 & Pangindar & kopi arabika & - \\
4 & STTU Julu & Gambir & Karet \\
5 & PGGS & Gambir & karet,kopi arabika,kemenyan \\
6 & Kerajaan & Karet & Karet \\
7 & Tinada & kopi arabika & - \\
8 & Siempat Rube & & \\
Tanaman Pangan & padi sawah & Jagung,kacang tanah \\
1 & Salak & padi sawah & jagung \\
2 & STTU Jehe & padi gogo & - \\
3 & Pangindar & padi sawah & jagung \\
4 & STTU Julu & padi sawah & Jagung,ubi kayu \\
5 & PGGS & padi sawah & jagung \\
6 & Kerajaan & padi sawah & Jagung,ubi kayu \\
7 & Tinada & padi sawah & Jagung,ubi jalar \\
8 & Siempat Rube & & \\
Hortikultura & Jeruk & durian,nenas \\
1 & Salak & Jeruk & durian \\
2 & STTU Jehe & - & - \\
3 & Pangindar & Jeruk & durian \\
4 & STTU Julu & Jeruk & durian \\
5 & PGGS & Jeruk & durian \\
6 & Kerajaan & Jeruk & durian \\
7 & Tinada & Jeruk & nenas \\
8 & Siempat Rube & & \\
\hline
\end{tabular}


Berdasarkan Tabel 2 didapatkan bahwa komoditas unggulan utama untuk tanaman perkebunan di Kecamatan Salak, STTU Jehe, PGGS dan Kerajaan adalah gambir. Kecamatan STTU Julu dan Siempat Rube komoditas unggulan utama perkebunan adalah kopi robusta sedangkan Kecamatan Tinada dan Pangindar adalah karet. Komoditas unggulan untuk tanaman pangan di Kecamatan Salak, STTU Jehe, STTU Julu, PGGS, Kerajaan, Tinada dan Siempat Rube adalah padi sawah sedangkan di Kecamatan Pangindar adalah padi gogo. Komoditas unggulan utama tanaman hortikultura di Kecamatan Salak, STTU Jehe, STTU Julu, PGGS, Kerajaan, Tinada dan Siempat Rube adalah jeruk sedangkan Kecamatan Pangindar tidak memiliki komoditas unggulan dan penunjang karena para petani disana hanya berkonsentrasi pada komoditas perkebunan dan tanaman pangan. Komoditas unggulan penunjang bervariasi di tiap kecamatan.

\section{Ketersediaan Lahan}

Ketersediaan lahan untuk pengembangan komoditas unggulan pertanian dan perkebunan di Kabupaten Pakpak Bharat masih luas. Hasil analisis sistem informasi geografis menunjukkan ketersediaan lahan untuk komoditas perkebunan seperti gambir, kopi arabika, karet, kelapa sawit seluas 61.477,19 ha dan untuk pertanian lainnya seperti jeruk, nenas, padi gogo dan lainnya seluas 29.182,56 ha. Pemerintah Kabupaten Pakpak Bharat menetapkan Kecamatan STTU Jehe sebagai wilayah pengembangan komoditas hortikultura dan selebihnya untuk pengembangan tanaman pangan. Dengan demikian ketersediaan lahan untuk hortikultura seluas 11.632,72 ha, tanaman pangan seluas 17.549,84 ha dan perkebunan seluas $61.477,19$ ha. Peta ketersediaan lahan disajikan pada Gambar 2.

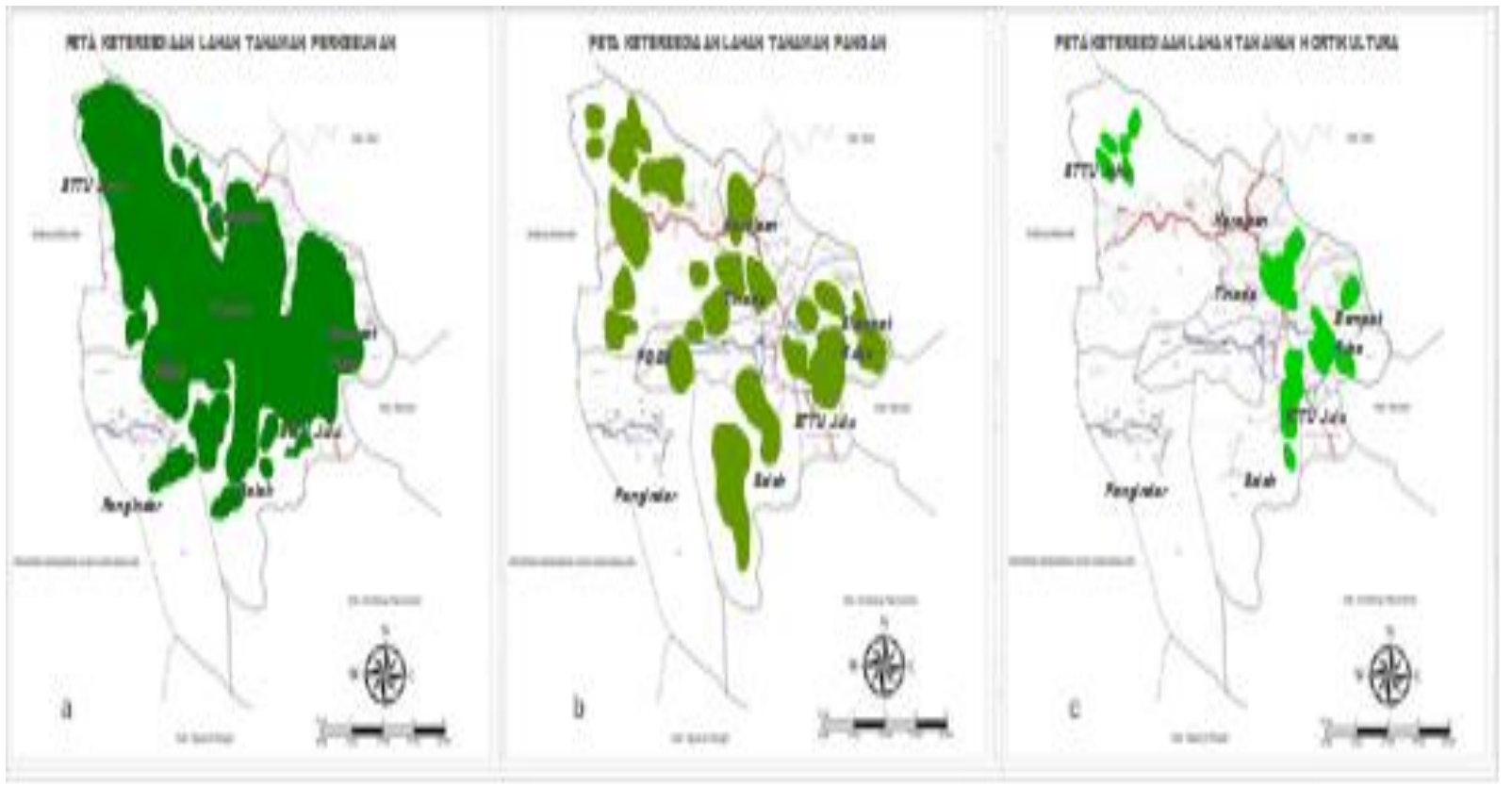

Gambar 2. Ketersediaan Lahan (a) perkebunan (b) pangan (c) hortikultura 


\section{Kesesuaian Lahan}

Berdasarkan Tabel 3 didapatkan bahwa luas kesesuaian lahan untuk perkebunan tergolong kelas kesesuaian $\mathrm{S} 3$ seluas 49.590,28 ha dan S2 seluas $11.761,35$ ha. Lahan yang tidak sesuai (N) dengan faktor pembatas temperatur tidak dapat dikembangkan. Kesesuaian lahan untuk komoditas pangan luas paling besar adalah kelas kesesuaian lahan S3 sebesar 13.940,97 ha dan S2 seluas 2.259,24 ha. Kesesuaian lahan untuk hortikultura yang terbesar adalah S3 dengan luas 6.052,73 ha, S2 seluas $3.118,34$ ha dan $\mathrm{S} 1$ seluas $2.461,65$ ha

Tabel 3. Kesesuaian Lahan Komoditas Unggulan

\begin{tabular}{|c|c|c|c|c|c|}
\hline Komoditas & Kelas & Sub Kelas & Faktor Pembatas & $\begin{array}{l}\text { Luas } \\
\text { (ha) }\end{array}$ & $\%$ \\
\hline \multirow[t]{16}{*}{ Perkebunan } & S1 & - & - & - & - \\
\hline & \multirow[t]{2}{*}{ S2 } & $\mathrm{S} 2 \mathrm{rc}$ & tekstur & $4.909,14$ & 7,99 \\
\hline & & S2warc & bk, tekstur & $6.852,21$ & 11,15 \\
\hline & \multirow[t]{7}{*}{ S3 } & S3wa & bk & $4.928,13$ & 8,02 \\
\hline & & S3oa & drainase & 768,68 & 1,25 \\
\hline & & S3tc & temp. & 589,82 & 0,96 \\
\hline & & S3eh & $\mathrm{kl}$ & $5.287,11$ & 8,60 \\
\hline & & S3waoa & bk, drainase & $2.173,56$ & 3,54 \\
\hline & & S3waeh & $\mathrm{bk}, \mathrm{kl}$ & $1.188,42$ & 1,93 \\
\hline & & S3oaeh & drainase,kl & $10.727,16$ & 17,45 \\
\hline & \multirow[t]{5}{*}{$\mathrm{S} 3$} & S3tcoa & temp., drainase & $11.629,23$ & 18,92 \\
\hline & & S3tceh & temp.,kl & $2.371,32$ & 3,59 \\
\hline & & S3tcwa & temp.,bk & $5.287,11$ & 8,60 \\
\hline & & S3tcwaoa & temp.,bk, drainase & $3.827,52$ & 6,23 \\
\hline & & S3tcwaeh & temp.,bk, kl & 812,22 & 1,32 \\
\hline & $\mathrm{N}$ & Ntc & temp. & 125,56 & 0,45 \\
\hline \multicolumn{2}{|c|}{ Jumlah } & & & $61.477,19$ & 100 \\
\hline \multirow[t]{8}{*}{ Pangan } & S1 & - & - & - & \\
\hline & \multirow[t]{3}{*}{$\mathrm{S} 2$} & $\mathrm{~S} 2 \mathrm{tc}$ & temp. & 1537,12 & 8,76 \\
\hline & & S2tceh & temp.,kl & 245,44 & 1.40 \\
\hline & & S2tcehoa & temp.,kl,drainase & 476,68 & 2,72 \\
\hline & \multirow[t]{2}{*}{ S3 } & S3tc & temp. & 5373,66 & 30,62 \\
\hline & & S3tceh & temp.,kl & 8567,31 & 48,82 \\
\hline & \multirow[t]{2}{*}{$\mathrm{N}$} & $\mathrm{Neh}$ & $\mathrm{kl}$ & 563,57 & 3,20 \\
\hline & & Ntc & temp. & 786,06 & 4,48 \\
\hline \multicolumn{2}{|l|}{ Jumlah } & & & $17.549,84$ & 100 \\
\hline \multirow[t]{4}{*}{ Hortikultura } & S1 & - & - & 2461,65 & 21,16 \\
\hline & $\mathrm{S} 2$ & S2ehrc & kl,kedalam tanah & 3118,34 & 26,81 \\
\hline & S3 & S3renr & $\mathrm{tt}$ & 1635,22 & 14,06 \\
\hline & & S3ehwarcnr & $\mathrm{kl}, \mathrm{ch}, \mathrm{tt}$ & 4417,51 & 37,97 \\
\hline Jumlah & & & & $11.632,72$ & 100 \\
\hline
\end{tabular}

Keterangan : $S 1=$ sangat sesuai, $S 2=$ cukup sesuai, $S 3=$ sesuai marginal, $N=$ tidak sesuai $b l=$ bulan kering, $k l=$ kelas lereng, temp. =temperatur, ch=curah hujan, tt=tekstur tanah 
Lahan Berpotensi Pengembangan Komoditas Pertanian Unggulan

Lahan yang berpotensi pengembangan untuk komoditas unggulan diperlukan untuk mengidentifikasi lahan yang berpotensi untuk ekstensifikasi

Lahan yang berpotensi pengembangan komoditas unggulan untuk kegiatan ekstensifikas perkebunan dan pangan masih sangat besar. Lahan yang berpotensi pengembangan untuk perkebunan seluas $29.466,39$ ha, terdiri dari 11.038,97 ha kelas kesesuaian S2 dan 18.427,42 ha kelas kesesuaian S3. Lahan yang berpotensi pengembangan untuk pangan seluas 10443,41 ha, terdiri dari 4600,98 ha kelas kesesuaian S2 dan 5842,43 ha kelas kesesuaian S3.

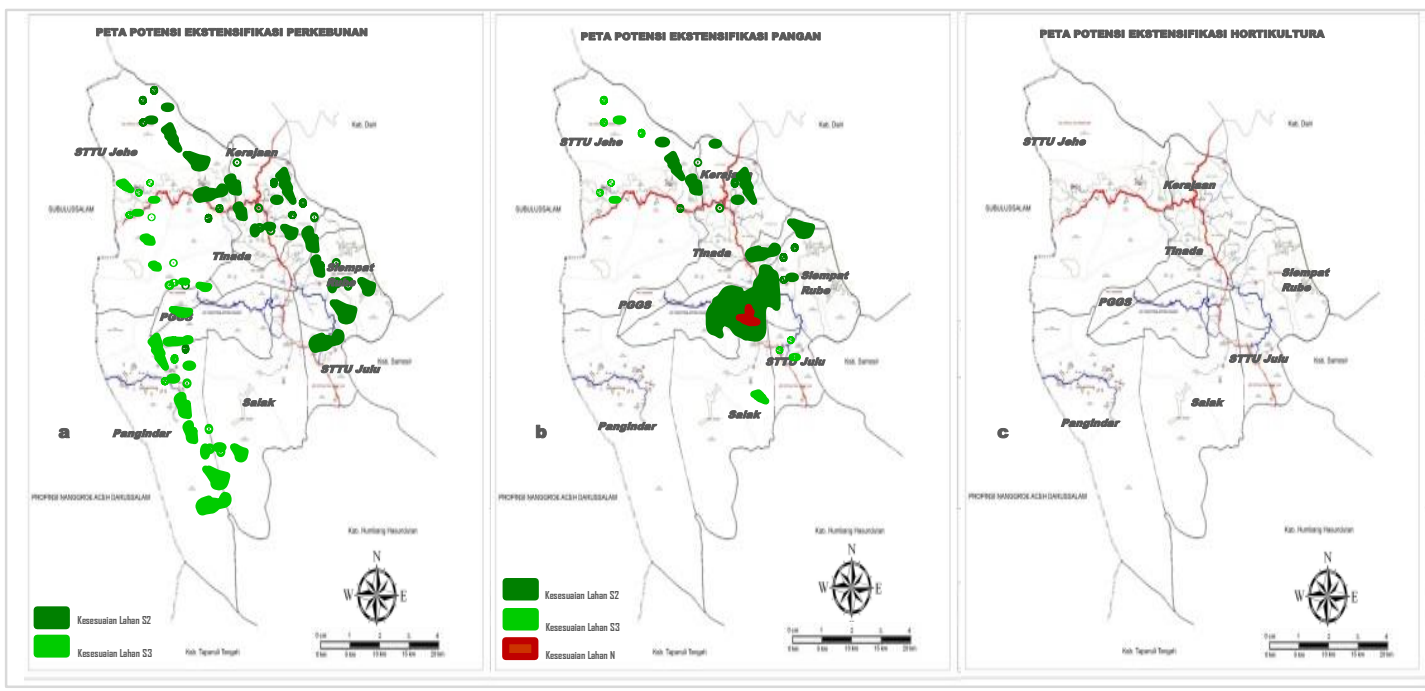

Gambar 3. Lahan Berpotensi Untuk Pengembangan (a) perkebunan (b) pangan (c) hortikultura

Tabel 4. Lahan Yang Berpotensi Pengembangan Untuk Komoditas Unggulan di Kab. Pakpak Bharat

\begin{tabular}{|c|c|c|c|c|c|c|c|}
\hline \multicolumn{4}{|c|}{ Perkebunan } & \multicolumn{4}{|c|}{ Pangan } \\
\hline \multirow[t]{2}{*}{ Kec. } & $\begin{array}{l}\text { Kes. } \\
\text { S2 }\end{array}$ & $\begin{array}{c}\text { Kes. } \\
\text { S3 }\end{array}$ & $\begin{array}{l}\text { Jlh } \\
\text { (ha) }\end{array}$ & Kec. & $\begin{array}{l}\text { Kes. } \\
\text { S2 }\end{array}$ & $\begin{array}{c}\text { Kes. } \\
\text { S3 }\end{array}$ & $\begin{array}{l}\text { Jlh } \\
\text { (ha) }\end{array}$ \\
\hline & $\begin{array}{l}\text { Luas } \\
\text { (ha) }\end{array}$ & $\begin{array}{l}\text { Luas } \\
\text { (ha) }\end{array}$ & & & $\begin{array}{l}\text { Luas } \\
\text { (ha) }\end{array}$ & $\begin{array}{l}\text { Luas } \\
\text { (ha) }\end{array}$ & \\
\hline Salak & $1.478,11$ & $2.562,78$ & $4.040,89$ & Salak & 276,34 & 881,78 & $1.158,12$ \\
\hline STTU Jehe & $1.732,43$ & $2.237,24$ & $3.969,67$ & STTU Jehe & 372,21 & 253,12 & 625,33 \\
\hline Pangindar & 983,12 & $1.892,24$ & $2.875,36$ & Pangindar & 678,31 & 878,48 & $1.556,79$ \\
\hline STTU Julu & $1.475,83$ & $2.721,67$ & 4197,5 & STTU Julu & 778,44 & 790,11 & $1.568,55$ \\
\hline PGGS & $2.183,73$ & $2.178,17$ & 4361,9 & PGGS & 345,77 & 647,84 & 993,61 \\
\hline Kerajaan & $1.072,22$ & $1.787,53$ & $2.859,75$ & Kerajaan & 434,55 & 547,88 & 982,43 \\
\hline Tinada & 935,27 & $2.569,33$ & 3504,6 & Tinada & 945,67 & 895,67 & $1.841,34$ \\
\hline S. Rube & $1.178,26$ & $2.478,46$ & $3.656,72$ & S. Rube & 769,69 & 947,55 & $1.717,24$ \\
\hline Jlh & $11.038,97$ & $18.427,42$ & $29.466,39$ & Jlh & $4.600,98$ & $5.842,43$ & $10.443,41$ \\
\hline
\end{tabular}

Keterangan : Kes. $=$ kesesuaian 


\section{Hirarki Wilayah}

Hasil perhitungan skalogram terhadap delapan kecamatan di Kabupaten Pakpak Bharat didapatkan tiga kelas hirarki. Hirarki 1 (tinggi) dengan IPK lebih dari 27.08 merupakan wilayah kecamatan yang tingkat pelayanan dan perkembangan wilayahnya tinggi yaitu Kecamatan Salak, STTU Jehe, Kerajaan. Hirarki 2 (sedang) dengan IPK sebesar 22.2-27.08 merupakan wilayah dengan tingkat perkembangan wilayah sedang yaitu Kecamatan Tinada dan Siempat Rube. Hirarki 3 (rendah) dengan IPK kurang dari 22.22 merupakan wilayah dengan tingkat perkembangan wilayah rendah yaitu Kecamatan Pangindar, STTU Julu dan PGGS.

\section{Arahan Pengembangan Komoditas Pertanian Unggulan}

Arahan pengembangan komoditas unggulan untuk perkebunan dilakukan berdasarkan pertimbangan luas lahan potensial terbesar, kelas kesesuaian lahan tertinggi, lahan yang kompak dan kelas hirarki wilayah kecamatan tertinggi. Arahan pengembangan pangan dilakukan berdasarkan pertimbangan kebijakan pemerintah daerah.
Pengembangan perkebunan diarahkan di Kecamatan STTU Jehe seluas 4.512,56 ha (Prioritas 1), Kecamatan Salak seluas 3.258,12 ha (Prioritas 2), Kecamatan Kerajaan seluas 1812,11 ha (Prioritas 3) dan Kecamatan Siempat Rube seluas 923,72 ha (Prioritas 4). Prioritas pengembangan lahan kopi robusta disajikan pada Tabel 5 .

Arahan pengembangan tanaman pangan diprioritaskan sesuai dengan arahan kebijakan pemerintah Kabupaten Pakpak Bharat untuk pengembangan lahan tanaman pangan baru di Kecamatan Pangindar. Sehingga arahan pengembangan lahan tanaman pangan baru dilakukan di Pangindar dengan luas $2.182,81$ ha. Intensifikasi tanaman pangan khususnya padi yang dilakukan adalah peningkatan indeks panen yang biasanya setahun 2 kali, pada kelas kesesuaian lahan S1 dan S2 dapat ditingkatkan menjadi 3 kali dalam setahun dengan penambahan pupuk, pemilihan bibit unggul, pemberantasan hama dan penyakit.

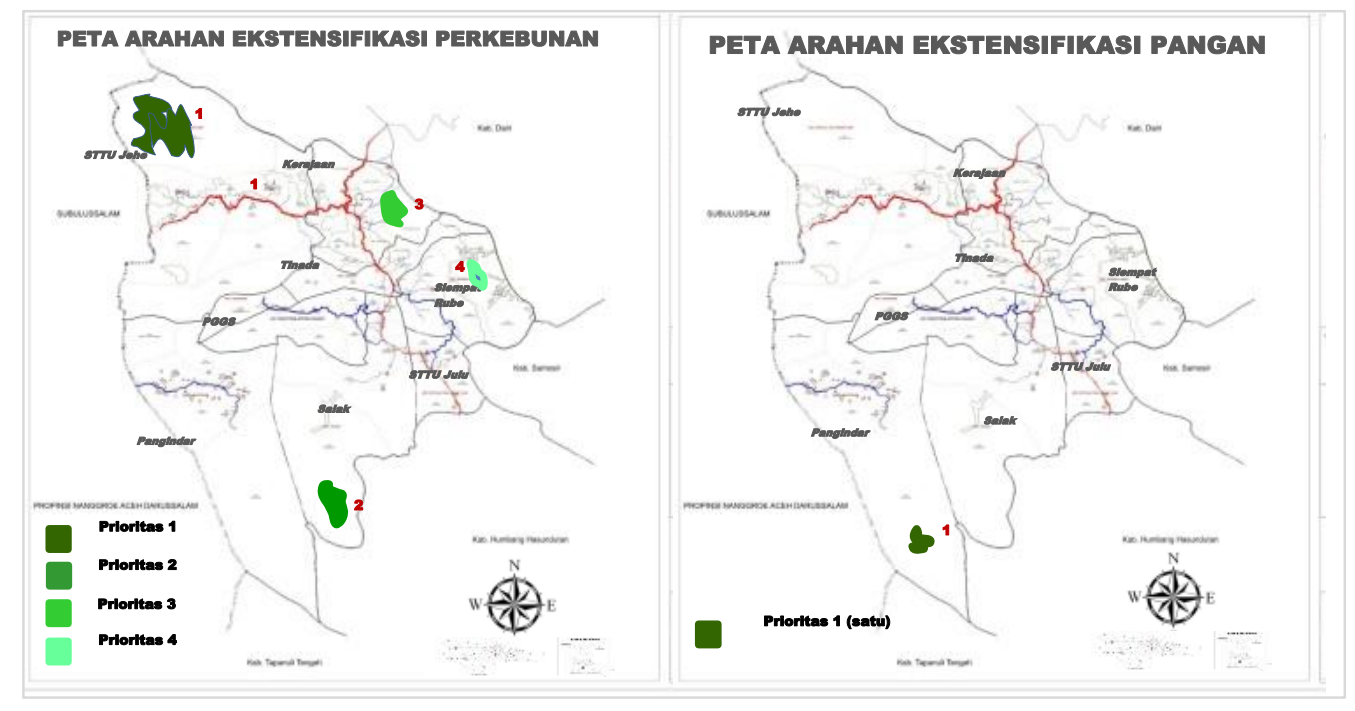

Gambar 4. Peta Arahan Ekstensifikasi Perkebunan dan Pangan 
Tabel 5. Prioritas Pengembangan Lahan Perkebunan

\begin{tabular}{lllll}
\hline \multirow{2}{*}{ Kriteria } & \multicolumn{4}{c}{ Prioritas Pengembangan Lahan Perkebunan } \\
\cline { 2 - 5 } & \multicolumn{1}{c}{1} & \multicolumn{1}{c}{2} & \multicolumn{1}{c}{4} \\
\hline Potensi lahan /luas lahan (ha) & $4.512,56$ & $3.258,12$ & 1812,11 & 923,72 \\
Kelas Kesesuaian lahan & $\mathrm{S} 2$ & $\mathrm{~S} 3$ & $\mathrm{~S} 3$ & $\mathrm{~S} 3$ \\
Kesatuan lahan & kompak & kompak & kompak & kompak \\
Hirarki kecamatan & 2 & 3 & 3 & 2 \\
\hline Keterangan S2=Cukup sesuai, S3=Sesuai marginal & & &
\end{tabular}

\section{SIMPULAN}

Komoditas unggulan utama di Kabupaten Pakpak Bharat untuk komoditas perkebunan di Kecamatan Salak, STTU Jehe, PGGS dan Kerajaan adalah tanaman gambir. Komoditas unggulan utama tanaman pangan di Kecamatan Salak, STTU Jehe, STTU Julu, PGGS, Kerajaan Tinada dan Siempat Rube adalah padi sawah dan komoditas unggulan utama tanaman hortikultura di Salak, STTU Jehe, STTU Julu, PGGS, Kerajaan Tinada dan Siempat Rube Utara adalah jeruk. Lahan yang berpotensi pengembangan untuk untuk komoditas unggulan tanaman perkebunan seluas $29.466,39$ ha, terdiri dari 11.038,97 ha kelas kesesuaian S2 dan 18.427,42 ha kelas kesesuaian S3. Lahan yang berpotensi pengembangan untuk komoditas unggulan tanaman pangan seluas 10443,41 ha, terdiri dari 4600,98 ha kelas kesesuaian S2 dan 5842,43 ha kelas kesesuaian S3. Hirarki wilayah masing-masing kecamatan adalah Kecamatan Salak, STTU Jehe, Kerjaan tergolong hirarki I, Tinada dan Siempat Rube tergolong hirarki II, Pangindar, STTU Julu dan PGGS tergolong hirarki III. Pengembangan komoditas unggulan tanaman perkebunan diarahkan di Kecamatan STTU Jehe seluas 4.512,56 ha (Prioritas 1), Kecamatan Salak seluas 3.258,12 ha (Prioritas 2), Kecamatan Kerajaan seluas 1812,11 ha (Prioritas 3) dan Kecamatan Siempat Rube seluas 923,72 ha
(Prioritas 4). Pengembangan komoditas unggulan tanaman pangan diprioritaskan di Kecamatan Pangindar seluas 2.182,81 ha.

\section{DAFTAR PUSTAKA}

Ameriyani,P. (2014). Perencanaan pengembangan Sub Sektor Perikanan Laut Di Lima

Kecamatan Di Kabupaten Rembang.Jurnal Economics Development Analysis. 3(1):225234

Blakely EJ. 1994. Planning Local Economic Development: Theory and Practice.2nd Edition. California (USA):International Education and Professional Publisher.

Boix LR, Zinck JA. 2008. Land use planning in the chaco plain (Burruyacu; Argentina). Part 1: Evaluating land use options to support crop diversification in an agricultural frontier area using physical land evaluation. Environmental Management. 42: 1043 - 1063.

[BPS] Badan Pusat Statistik Kabupaten Pakpak Bharat. 2018. Pakpak Bharat Angka Tahun 2018. Pakpak Bharat (ID): Badan Pusat Statistik.

[BBPPSDLP] Balai Besar Penelitian dan Pengembangan Sumberdaya Lahan Pertanian. 2011. Petunjuk Teknis Evaluasi Lahan Untuk Komoditas Pertanian . Bogor (ID): BBPPSDLP Badan Litbang Kementerian Pertanian. 
Chiang S. 2008. Location quotient and trade. Annual Regional Science. 43: $339-414$

[FAO] Food and Agriculture Organization. 1976. A Framework for Land Evaluation.

Rome (IT): Soil Bull. No. 32, FAO.

Lillesand MT, Kiefer RW. 1993.

Penginderaan Jauh dan Interpretasi

Citra.

[Terjemahan]. Yogyakarta (ID) :

Gadjah Mada University Press.

Manik, T.R., Adrianto, D.W., Subagiyo,A. 2013. Kajian

Pengembangan Kawasan

Agropolitan Seroja Kabupaten

Lumajang. Jurnal Tata Kota dan

Daerah. 5(1):65-76

Nowar, W.,Baskoro,D.P.T.,Tjahjono,B. 2015. Analisis Kesesuaian Lahan Komoditas

Unggulan dan Arahan Pengembangannya di Wilayah

Kabupaten Cianjur.Jurnal

Tata Loka.17(2):87-98.

Ogunlade MO, Aikpokpodion PO, Braimoh AK. 2012. Land suitability evaluation for cocoa production in Nigeria using fuzzy methodology. International Journal of

Suitable Crop Production. 7: 13 20.

Panuju, D.R., Rustiadi, E. 2013. Teknik Analisis Perencanaan

Pengembangan Wilayah.

Bogor (ID): Departemen Ilmu Tanah Dan Sumberdaya Lahan IPB

Raharjo, S.,Widiatmaka, Sudadi,U. 2015. Analisis Kesesuaian Lahan Untuk Komoditas

Sayuran Unggulan di Kabupaten Batang.Jurnal pengelolaan Sumberdaya alam dan Lingkungan. 5(1) :33-41

Setiawati, A.R., Sitorus, S.R.P, Widiatmaka. 2016. Perencanaan Penggunaan Lahan
Komoditas Unggulan Perkebunan di Kabupaten Tanah Datar.Jurnal Tata Loka 18(3):131-140

Sitorus, S.R.P.,Mulya,S.P., Iswati,A., Panuju,D.R.,.Iman.

L.O.S. 2014.Teknik

Penentuan Komoditas Unggulan Pertanian Berdasarkan Potensi Wilayah dalam Rangka Pengembangan Wilayah. Dalam: Astuti,P., Manan, M., Dinata, A., Asteriani, F (Editor). Prosiding Seminar Nasional ASPISustainable and Resilient Cities and Regions; Pekan baru 1718Oktober2014. Pekanbaru (ID): Universitas Islam Riau hlm 396406.

Sitorus,S.R.P., Purnamasari, A., Mulya, S.P. 2015. Analisis Keterkaitan Penggunaan

Lahan. Rencana Pola Ruang dan Hirarki Wilayah di Kota Cilegon. Dalam: Putra,

G.P.A., Sudharsana, M.G., Sukamara, N (Editor). ProsidingSeminar Nasional Tata

Ruang dan SPACE II; Denpasar 1517Oktober2015;Denpasar (ID): Universitas Hindu Indonesia hlm 501-508.

Widiatmaka,

Ambarwulan,W.,Sutomo,B.,Hamz ah,U.,Warsono.P. 2014. Perancangan

Tataguna Lahan Dan Tata Ruang Kawasan Perkotaan Berbasisi Pertanian:Studi Kasus Kota Terpadu Mandiri Transmigrasi Mesuji. Provinsi Lampung. Prosiding Seminar Nasional Multi Disiplin Ilmu.Jakarta 10 Mei 2014. Penyelenggara: Universitas Budi luhur hlm 98-105

Wirosoedarmo,R.,Sutanhaji,A.T.,Kurnia ti,E., Wijayanti,R. 2011. Evaluasi Kesesuaian 
Lahan Untuk Tanaman Jagung Menggunakan Analisis Spasial. Jurnal

Agritech.31(1):71-78

Yanis, M.N.,Guchi,H.,Sembiring,M. 2014. Evaluasi Kesesuaian Lahan Kabupaten Dairi

Untuk Tanaman Kopi Robusta (coffea robusta lindl). Jurnal Agroteknologi.2(4):1464-1478
Yustian, Sudadi,U., Ardiansyah,M. 2014. Arahan Dan Strategi Pengembangan Lahan

Sawah Di Wilayah Pesisir Provinsi Kalimantan Barat. Jurnal Tanah dan

lingkungan.16(1):31-37 